\title{
Repair of the Chronic Rupture of tendo Achilles Tendon using Peroneus Brevis Tendon
}

\author{
${ }^{1}$ Hari O Aggarwal, ${ }^{2}$ Manjit Singh, ${ }^{3}$ Sanjeev Sareen, ${ }^{4}$ Deepak Vashisht
}

\section{ABSTRACT}

Aim: To report 20 patients who underwent repair of chronic rupture of tendo Achilles tendon with peroneus brevis tendon.

Materials and methods: Records of 6 women and 14 men aged 26 to 58 (mean, 36) years who underwent repair of chronic rupture of tendo Achilles tendon with peroneus brevis tendon transfer were reviewed. Patients were evaluated at 3, 9, and 12 months using the foot and ankle outcome score (FAOS) questionnaire.

Results: Out of 20 patients, 4 developed superficial skin complications which healed gradually in 3 patients, and 1 patient underwent skin grafting surgery. No patient had a re-rupture of the tendo Achilles tendon. At the 1-year follow-up, all patients achieved good functional outcome in terms of the FAOS.

Conclusion: Repair of chronic rupture of tendo Achilles tendon with peroneus brevis tendon transfer achieved good functional outcome.

Keywords: Tendo Achilles tendon, Chronic rupture, Tendon transfer.

How to cite this article: Aggarwal HO, Singh M, Sareen S, Vashisht D. Repair of the Chronic Rupture of tendo Achilles Tendon using Peroneus Brevis Tendon. J Foot Ankle Surg (Asia-Pacific) 2017;4(1):30-34.

Source of support: Nil

Conflict of interest: None

\section{INTRODUCTION}

Historically, acute tendo Achilles tendon rupture was regarded as a rare injury comprising less than $0.2 \%$ of general population. ${ }^{1}$ However, in the past decade, the incidence of tendo Achilles tendon rupture has increased. ${ }^{2}$ At present, tendo Achilles tendon is the most commonly ruptured tendon of the lower extremity and may account for up to $40 \%$ of all operated tendon ruptures. ${ }^{3}$ The increase in frequency is thought to be due to an increased interest and participation in recreational sports by middle-aged and older patients. ${ }^{4}$

\footnotetext{
${ }^{1,3}$ Assistant Professor, ${ }^{2}$ Professor, ${ }^{4}$ Senior Resident

${ }^{1-4}$ Department of Orthopaedics, Government Medical College Patiala, Punjab, India
}

Corresponding Author: Hari O Aggarwal, Assistant Professor Department of Orthopaedics, Government Medical College Patiala, Punjab, India, Phone: +919814005998, e-mail: dr.hariom@yahoo.com
In acute ruptures, often a snapping sensation is felt in posterior aspect of the ankle, with weight bearing on the affected side. There is often a palpable gap between the ruptured ends. ${ }^{5}$ In a study of 57 patients with acute Achilles rupture, 19 of them reported to be painless. ${ }^{6}$ Patients with tendo Achilles tendon rupture are frequently unable to stand on the toes of the involved side; however, active planter flexion may be intact due to partial ruptures, recruitment of plantar flexors, and an intact plantaris muscle. The lack of pain and no obvious loss of plantar flexion can be misleading, and in up to 20 to $25 \%$ of cases, the diagnosis is missed initially. ${ }^{7}$ The management of chronic tendo Achilles tendon rupture is usually different from that of acute rupture, as the tendon ends have retracted.

The blood supply to this area is poor, and freshening of the tendon ends is necessary when they are shredded. End-to-end repair of such ruptured tendons is difficult and prone to failure, infection, and skin necrosis. Hence, even in fresh ruptures, the repair of tendo Achilles tendon should be augmented with tendon grafting, tendon transfer, or reinforcement with synthetic materials. The tendon of the flexor hallucis longus, plantaris, and peroneus brevis are often used for augmentation. ${ }^{8-10}$ Peroneus brevis tendon transfer was popularized by Perez-Teuffer. ${ }^{11}$ In the original technique, the harvested peroneus brevis tendon was passed through a transosseous drill hole in the calcaneus. Subsequently, Turco and Spinella ${ }^{12}$ modified the technique by passing the peroneus brevis tendon through the distal stump of the tendo Achilles tendon.

We report 20 patients who underwent repair of tendo Achilles tendon ruptures with peroneus brevis tendon transfer.

\section{MATERIALS AND METHODS}

Records of 6 women and 14 men aged 18 to 56 (mean, 36) years who underwent repair of chronic rupture of tendo Achilles tendon with peroneus brevis tendon transfer in the Department of Orthopaedics, Government Medical College, Patiala, Punjab, India between August 2011 and March 2015 were reviewed. All the ruptures were secondary to sports activities, industrial accident, motor vehicle injuries, or sharp cuts. Few patients had history of multiple steroid injections at the tendo Achilles tendon.

Our surgical technique was based on the study by Turco and Spinella. ${ }^{12}$ At our institution, regional anesthesia 


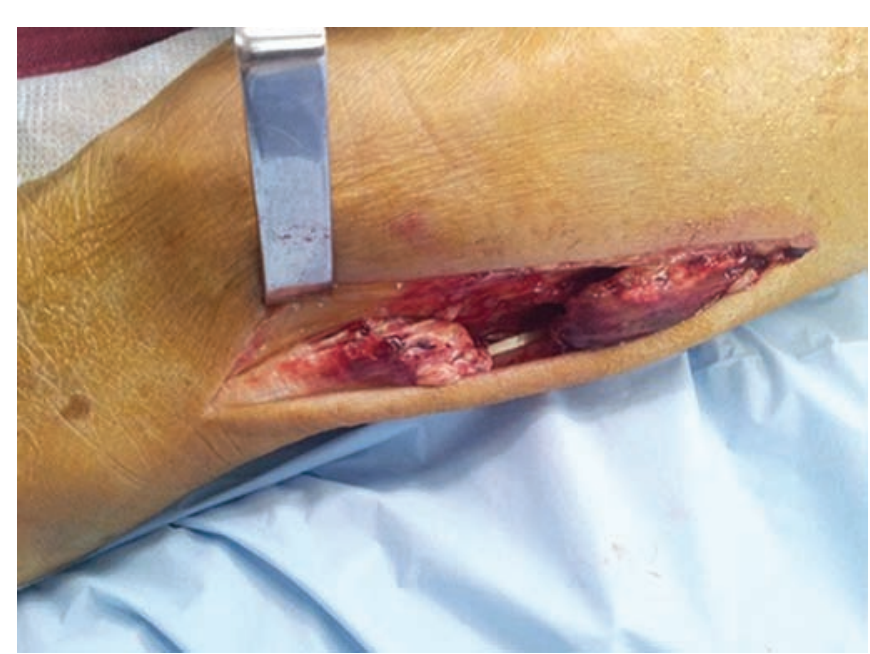

Fig. 1: Incised tendo Achilles sheath and torn tendon

is preferred for this procedure. The patient is placed prone with feet protruding over the edge of the operating table. Both legs are prepared and draped, allowing intraoperative comparison to adjust the tension of the reconstruction.

An upper thigh tourniquet was used. A posterolateral longitudinal incision was made by maintaining the thick skin flaps as skin is poorly vascular in this area. Care was taken to avoid damage to the sural nerve. The tendo Achilles tendon was exposed using a longitudinal incision. The ruptured tendon edges were trimmed and scar tissue was resected. Through a separate incision, the peroneus brevis tendon was identified at the base of the fifth metatarsal (Figs 1 and 2).

The peroneus brevis tendon is then detached from its insertion over base of fifth metatarsal and mobilized proximally. The tendon is then delivered through the primary wound using gentle continuous traction as it is pulled through the inferior peroneal retinaculum. In this fashion, the tendon of the peroneus brevis retains its blood supply from the intermuscular septum. The peroneus brevis tendon was then passed lateral to medial through a mid-coronal slit in the distal stump of the tendo Achilles tendon and then reversed upward up to the proximal end of the tendo Achilles tendon (Fig. 3). The tendon graft was sutured to the distal and proximal stump of the tendo Achilles tendon using multiple interrupted sutures with No. 2 Ethibond suture. The resting equinus position of the normal leg was noted, so as to produce the same degree of equinus in the injured leg. In patients with an insufficient distal stump, the peroneus brevis tendon was passed through a drill hole at calcaneal tuberosity.

Postoperatively, an above-knee posterior plaster was applied, with the ankle at 10 to $15^{\circ}$ plantarflexion and the knee at $15^{\circ}$ of flexion for 4 weeks. Patients were advised to keep the operated limb elevated to minimize the swelling. Active movement of the toes and isometric exercises of the

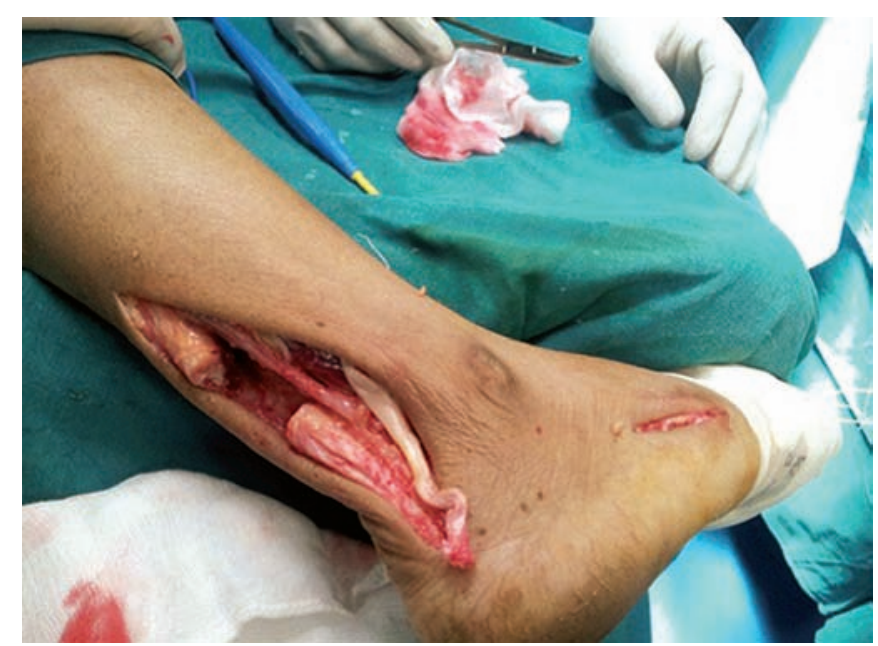

Fig. 2: Freshened torn ends of tendo Achilles and peroneus brevis harvested from insertion via a mini incision and brought through the primary wound

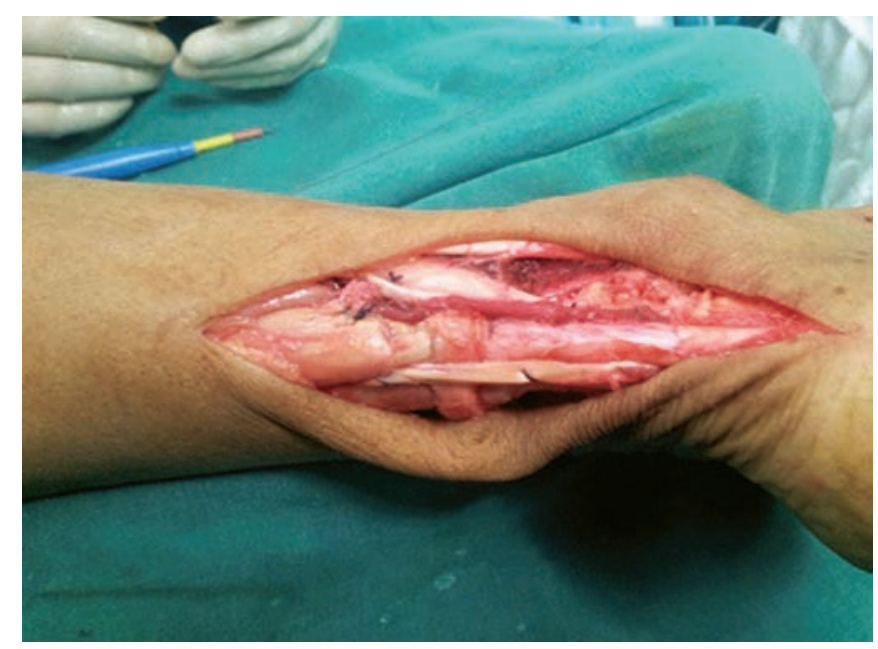

Fig. 3: Augmentation of repair of Achilles tendon using peroneus brevis tendon

calf muscles were encouraged. At week 2, sutures were removed in the outpatient department and an above-knee plaster was continued up to 4 weeks postoperatively. This was followed by below-knee cast with ankle in neutral position for another 4 weeks.

Knee movements were started with the limb in belowknee cast and the patient was allowed to walk with the help of walking aid without putting weight over the affected limb. Toe touch weight bearing with the help of a walking aid was allowed at 6 weeks after surgery. At 8 weeks after surgery, plaster was removed and the patient was allowed to walk with full weight bearing. A progressive strengthening rehabilitation program was followed. Patients were seen by a trained physiotherapist and taught to perform gentle mobilization of ankle focusing on plantar flexion, inversion, and eversion. They were restricted from running for additional 6 weeks and limited from return to sports until 6 months from time of surgery. Patients were evaluated at 3, 9, and 
12 months giving the foot and ankle outcome score (FAOS) questionnaire, which consisted of five subscales: Pain, other symptoms, activities of daily living, function in sports and recreation, and foot and ankle-related quality of life. Each question was scored 0 to 4 . A normalized score (4 indicating no symptoms and 0 indicating severe symptoms) was calculated for each subscale. Patients were followed up every 15 days for the first 2 months and then every month for the next 3 months, and then at 3-monthly interval till 1 year.

\section{RESULTS}

We have treated 20 patients with chronic rupture of tendo Achilles using this technique. All patients were able to walk on tiptoe at 12 months follow-up and no patient walked with limp. Out of 20 patients, 4 developed superficial skin complications (edge necrosis and/or inflammation) that healed gradually in 3 patients with regular dressing over 2 to 4 weeks and 1 patient has to undergo skin grafting procedure by plastic surgeon. No patient had a rerupture of the tendo Achilles tendon.

There was improvement in mean FAOS of each subscale from 3 to 12 months as shown in Table 1. At 1-year follow-up, all patients have achieved good functional outcome in terms of the FAOS and were satisfied with the procedure.

\section{DISCUSSION}

In tendo Achilles tendon ruptures, the overlying skin and subcutaneous tissue are often devascularized and contaminated. The torn tendon ends may be so shred-

Table 1: Mean FAOS at 3, 9 and 12 months follow-up

\begin{tabular}{lllll}
\hline Sl. & & $\begin{array}{l}\text { At 3 } \\
\text { months }\end{array}$ & $\begin{array}{l}\text { At } 9 \\
\text { months }\end{array}$ & $\begin{array}{l}\text { At 12 } \\
\text { months }\end{array}$ \\
\hline 1 & Painscale & 64 & 80 & 90 \\
2 & Other symptoms & 70 & 82 & 92 \\
3 & Activities of daily living & 60 & 76 & 90 \\
4 & $\begin{array}{l}\text { Function in sport and recreation } \\
5\end{array}$ & 56 & 60 & 79 \\
Foot and ankle-related quality & 55 & 76 & 90 \\
& of life & & & \\
\hline
\end{tabular}

ded and necessitate trimming. End-to-end tendon repair is difficult and prone to failure and wound healing problems. ${ }^{13}$

Wound complications tend to occur at the repair site, because of increased tissue bulk and compromised blood supply. ${ }^{14}$ In one study, about $16 \%$ of surgically repaired tendo Achilles tendons developed wound complications. ${ }^{15}$ In another study, a mere $1.5 \%$ infection rate occurred in 67 tendo Achilles tendon repairs, but whether the injuries were open or closed was not mentioned. ${ }^{16}$ The infection rate is usually higher in compound ruptures. The thin subcutaneous tissue over the tendo Achilles tendon, the limited blood supply, and mobilization of the skin all contribute to higher complication rates. ${ }^{17,18}$ In our study, 4 patients out of 20 developed superficial skin complications that healed gradually in 3 patients with conservative treatment and 1 patient required skin grafting. The results of our study were comparable with the study of Singh et al. ${ }^{19}$ as shown in Table 2.

The risk of operating in poorly vascularized skin can be reduced by handling of tissues and by maintaining thick skin flaps throughout the procedure. ${ }^{5}$

Tendo Achilles tendon repair is commonly augmented with the plantaris tendon, peroneus brevis tendon, and flexor hallucis longus tendon. ${ }^{5,9,10}$ The latter two have comparable mechanical properties. ${ }^{20}$ Plantar flexors are the muscles that push off the ground during walking. ${ }^{21}$ Harvesting the plantar flexors results in weakening the push-off phase of walking, and is distressing, particularly in young persons. ${ }^{21,22}$

After peroneus brevis tendon transfer, the strength of eversion may be mildly weakened but that of plantar flexion can be maintained. ${ }^{23}$ The two peroneal muscles contribute only $4 \%$ of the work capacity for plantar flexion, but for eversion the peroneus brevis tendon contributes about $28 \%$ of the total work strength. ${ }^{24}$ Thus, the use of the peroneus brevis tendon may cause a strength deficit in eversion of the ankle but a negligible deficit in planter flexion. Nonetheless, the peroneus longus, which is the major evertor of the hind foot, takes over functions of the peroneus brevis and continues to maintain the transverse arch. $^{25}$

Table 2: Comparison of mean FAOS of present study with the reference study at 3, 9, and 12 months follow-up

\begin{tabular}{|c|c|c|c|c|c|c|c|}
\hline \multirow[b]{3}{*}{ SI. no. } & \multirow[b]{3}{*}{ Subscale } & \multicolumn{6}{|c|}{ Observed mean FAOS compared with study by Singh et a $1{ }^{19}$ ("reference study") } \\
\hline & & \multicolumn{2}{|c|}{ At 3 months } & \multicolumn{2}{|c|}{ At 9 months } & \multicolumn{2}{|c|}{ At 12 months } \\
\hline & & $\begin{array}{l}\text { Present } \\
\text { study }\end{array}$ & $\begin{array}{l}\text { Reference } \\
\text { study }\end{array}$ & $\begin{array}{l}\text { Present } \\
\text { study }\end{array}$ & $\begin{array}{l}\text { Reference } \\
\text { study }\end{array}$ & $\begin{array}{l}\text { Present } \\
\text { study }\end{array}$ & $\begin{array}{l}\text { Reference } \\
\text { study }\end{array}$ \\
\hline 1 & Pain & 64 & 61.3 & 80 & 82.9 & 90 & 95.2 \\
\hline 2 & Other symptoms & 70 & 58.3 & 82 & 77.8 & 92 & 91.4 \\
\hline 3 & Activities of daily living & 60 & 53 & 76 & 76.5 & 90 & 90.7 \\
\hline 4 & Function in sport and recreation & 56 & 51.3 & 60 & 70.6 & 79 & 95.9 \\
\hline 5 & Foot and ankle-related quality of life & 55 & 55.8 & 76 & 77.4 & 90 & 89.2 \\
\hline
\end{tabular}


Gallant et $\mathrm{al}^{25}$ assessed eversion and plantar flexion strength after repair of tendo Achilles tendon rupture using peroneus brevis tendon transfer and found mild objective eversion and plantar flexion weakness. However, subjective assessment revealed no functional compromise. We have not come across any hindfoot varus deformities in our patients following this procedure. Nonetheless, in our patients, ankle movement exercise was performed during rehabilitation. ${ }^{22}$

The plantaris tendon may not be present in all individuals or capable of producing a strong reconstruction because of its thin structure, although it may be hypertrophied after chronic tears. ${ }^{26,27}$

The flexor hallucis longus tendon is an alternative, but its detachment from insertion can cause forefoot morbidity. ${ }^{10}$ In addition, there may be weakness of the hallux, reduced pressure under the great toe, and impaired load transfer to the metatarsal heads resulting in gait asymmetry, ${ }^{28}$ as well as decreased flexion power at the interphalangeal joints. ${ }^{29}$ This may be troublesome in young athletic patients, as it may impair the push-off phase in running activities.

The rupture sites may exhibit profound biochemical and gene expression changes and result in degeneration and reduction in tendon strength, even after end-toend repair. ${ }^{30}$ Augmentation with tendon transfers may supply healthy tissues to the area with degenerative changes and aid healing. Furthermore, the muscular belly of the peroneus brevis tendon is close to the tendinous part of the tendo Achilles tendon (which is less vascular and compromised by the surgery itself) and thus acts as a muscular flap that promotes vascularization of the repaired tendon.

\section{CONCLUSION}

Results of reconstruction of chronic rupture of tendo Achilles tendon using peroneus brevis tendon show a strong and stable repair that allows movements with early weight bearing with favorable clinical results. Care must be taken to prevent wound problems and deep infection.

\section{REFERENCES}

1. Cetti R, Christensen SE, Ejsted R, Jensen NM, Jorgensen U. Operative versus non-operative treatment of Achilles tendon rupture. A prospective randomized study and review of the literature. Am J Sports Med 1993 Nov-Dec;21(6):791-799.

2. Maffulli N, Waterston SW, Squair J, Reaper J, Douglas AS. Changing incidence of Achilles tendon rupture in Scotland: a 15-year study. Clin J Sport Med 1999 Jul;9(3):157-160.

3. Habusta SF. Bilateral simultaneous rupture of the Achilles tendon. A rare traumatic injury. Clin Orthop Relat Res 1995 Nov;320:231-234.

4. Coughlin, M.; Mann, R.; Saltzman, C. Disorders of tendons. In: Coughlin M, Mann RA, Saltzman CL, editors. Surgery of the foot and ankle. 8th ed. Philadelphia, PA: Mosby, Inc.; 2007. p. 1249-1261.

5. McClelland D, Maffulli N. Neglected rupture of the Achilles tendon: reconstruction with peroneus brevis tendon transfer. Surgeon 2004 Aug; 2(4):209-213.

6. Christensen I. Rupture of the Achilles tendon: analysis of 57 cases. Acta Chir Scand 1953 Aug;106(1):50-60.

7. Maffulli N. Clinical tests in sports medicine: more on Achilles tendon. Br J Sports Med 1996 Sep;30(3):250.

8. Maffulli N, Spiezia F, Longo UG, Denaro V. Less-invasive reconstruction of chronic Achilles tendon ruptures using a peroneus brevis tendon transfer. Am J Sports Med 2010 Nov;38(11):2304-2312.

9. Dalal RB, Zenios M. The flexor hallucis longus tendon transfer for chronic tendo-achilles ruptures revisited. Ann R Coll Surg Engl 2003 Jul;85(4):283.

10. Lynn TA. Repair of the torn Achilles tendon, using the plantaris tendon as a reinforcing membrane. J Bone Joint Surg Am 1966 Mar;48(2):268-272.

11. Perez-Teuffer A. Traumatic rupture of the Achilles tendon: reconstruction by transplant and graft using the lateral peroneus brevis. Orthop Clin North Am 1974 Jan;5(1):89-93.

12. Turco V, Spinella AJ. Team physician \#2. Peroneus brevis transfer for Achilles tendon rupture in athletes. Orthop Rev 1988;17(8):827-828.

13. Kumta SM, Maffulli N. Local flap covering for soft tissue defects following open repair of Achilles tendon rupture. Acta Orthop Belg 2003 Feb;69(1):59-66.

14. Boopalan PR, Jepegnanam TS, Titus VT, Prasad SY, Chittaranjan SB. Open infected Achilles tendon injury reconstruction of tendon with fascia lata graft and soft tissue cover with a reverse flow sural flap. Foot Ankle Surg 2008 Feb;14(2):96-99.

15. Dalton GP, Wapner KL, Hecht PJ. Complications of Achilles and posterior tibial tendon surgeries. Clin Orthop Relat Res 2001 Oct;391:133-139.

16. Mellor SJ, Patterson MH. Tendo Achilles rupture; surgical repair is a safe option. Injury 2000 Sep;31(7):489-491.

17. Aldam $\mathrm{CH}$. Repair of calcaneal tendon ruptures. A safe technique. J Bone Joint Surg Br 1989 May;71(3):486-488.

18. Massoud EI. Repair of fresh open tear of Achilles tendon tension regulation at the suture line. Foot Ankle Surg 2011 Sep;17(3):131-135.

19. Singh A, Nag K, Roy SP, Gupta RC, Gulati V, Agrawal N. Repair of Achilles tendon ruptures with peroneus brevis tendon augmentation. J Orthop Surg (Hong Kong) 2014 Apr;22(1):52-55.

20. Sebastian H, Datta B, Maffulli N, Neil M, Walsh WR. Mechanical properties of reconstructed Achilles tendon with transfer of peroneus brevis or flexor hallucis longus tendon. J Foot Ankle Surg 2007 Nov-Dec;46(6):424-428.

21. Ferris L, Sharkey NA, Smith TS, Matthews DK. Influence of extrinsic plantar flexors on forefoot loading during heel rise. Foot Ankle Int 1995 Aug;16(8):464-473.

22. Jacob HA. Forces acting in the forefoot during normal gait an estimate. Clin Biomech (Bristol, Avon) 2001 Nov;16(9): 783-792.

23. Pintore E, Barra V, Pintore R, Maffulli N. Peroneus brevis tendon transfer in neglected tears of the Achilles tendon. J Trauma 2001 Jan;50(1):71-78.

24. Clarke HD, Kitaoka HB, Ehman RL. Peroneal tendon injuries. Foot Ankle Int 1998 May;19(5):280-288.

25. Gallant GG, Massie C, Turco VJ. Assessment of eversion and plantar flexion strength after repair of Achilles tendon 
rupture using peroneus brevis tendon transfer. Am J Orthop (Belle Mead NJ) 1995 Mar;24(3):257-261.

26. Incavo SJ, Alvarez RG, Trevino SG. Occurrence of the plantaris tendon in patients sustaining subcutaneous rupture of the Achilles tendon. Foot Ankle 1987 Oct;8(2):110-111.

27. Coull R, Flavin R, Stephens MM. Flexor hallucis longus tendon transfer: evaluation of postoperative morbidity. Foot Ankle Int 2003 Dec;24(12):931-934.

28. Hahn F, Maiwald C, Horstmann T, Vienne P. Changes in plantar pressure distribution after Achilles tendon augmentation with flexor hallucis longus transfer. Clin Biomech (Bristol, Avon) 2008 Jan;23(1):109-116.

29. Richardson DR, Willers J, Cohen BE, Davis WH, Jones CP, Anderson RB. Evaluation of the hallux morbidity of singleincision flexor hallucis longus tendon transfer. Foot Ankle Int 2009 Jul;30(7):627-630.

30. Karousou E, Ronga M, Vigetti D, Passi A, Maffulli N. Collagens, proteoglycans, MMP-2, MMP-9 and TIMPs in human Achilles tendon rupture. Clin Orthop Relat Res 2008 Jul;466(7):1577-1582. 